\title{
Ethanol, 3,4-Methylenedioxymethamphetamine (Ecstasy) and Their Combination: Long-Term Behavioral, Neurochemical and Neuropharmacological Effects in the Rat
}

\author{
Jean-Christophe Cassel*,', Céline Riegert ${ }^{1,2}$, Susanne Rutz ${ }^{2}$, Julie Koenig', Katharina Rothmaier ${ }^{2}$, \\ Brigitte Cosquer', Christine Lazarus', Anja Birthelmer', Hélène Jeltsch ${ }^{1}$, Byron C Jones ${ }^{3}$ and Rolf Jackisch $^{2}$ \\ 'Laboratoire de Neurosciences Comportementales et Cognitives, UMR 7521, CNRS/Université Louis Pasteur, GDR 2905 CNRS, IFR 37 \\ Neurosciences, Strasbourg, France; ${ }^{2}$ Institut für Experimentelle und Klinische Pharmakologie und Toxikologie der Universität Freiburg, \\ Neuropharmakologisches Labor, Freiburg, Germany; ${ }^{3}$ Biobehavioral Health, The Pennsylvania State University, University Park, PA, USA
}

\begin{abstract}
This study investigated long-term behavioral, neurochemical, and neuropharmacological effects of ethanol-( \pm )-3,4-methylenedioxymethamphetamine (MDMA, ecstasy) combinations. Over 4 consecutive days, male Long-Evans rats received $1.5 \mathrm{~g} / \mathrm{kg}$ ethanol and $/$ or $10 \mathrm{mg} / \mathrm{kg}$ MDMA, or saline. Rectal temperatures were taken in some rats. Starting 4 days after the last injection, we tested working memory, sensory-motor coordination, and anxiety. Subsequently, we measured cortical, striatal, septal, and hippocampal monoamines (last MDMA injection-euthanasia delay: 20 days), or electrically evoked release of serotonin (5-HT) in cortical and hippocampal slices, and its modulation in the presence of CP 93, 129 (3-(1,2,5,6-tetrahydropyrid-4-yl)pyrrollo[3,2-b]pyrid-5-one) or methiotepin (last MDMA injection-euthanasia delays: 3-6 weeks). Ethanol attenuated the MDMA-induced hyperthermia, but only on the first day. In the longterm, MDMA reduced 5-HT and 5-hydroxyindoleacetic acid (5-HIAA) content in most brain regions. The behavioral and neurochemical effects of the ethanol-MDMA combination were comparable to those of MDMA alone; sensory-motor coordination was altered after ethanol and/or MDMA. In hippocampal slices from rats given ethanol and MDMA, the CP 93, I29-induced inhibition and methiotepininduced facilitation of 5-HT release were stronger and weaker, respectively, than in the other groups. This is the first study addressing long-term effects of repeated MDMA and $\mathrm{EtOH}$ combined treatments in experimental animals. Whereas the drug combination produced the same behavioral and neurochemical effects as MDMA alone, our neuropharmacological results suggest that MDMA-EtOH interactions may have specific long-term consequences on presynaptic modulation of hippocampal 5-HT release, but not necessarily related to MDMA-induced depletion of 5-HT. Thus, it is likely that the psycho(patho)logical problems reported by ecstasy users drinking alcohol are not solely due to the consumption of MDMA.

Neuropsychopharmacology (2005) 30, I870- 1882. doi:I0. I038/sj.npp. I 3007| 4; published online 23 March 2005
\end{abstract}

Keywords: 5-HT IB receptor ligands; cortex; hippocampus; MDMA; serotonin release; toxicity

\section{INTRODUCTION}

The amphetamine derivative ( \pm )-3,4-methylenedioxymethamphetamine (MDMA, ecstasy), first patented in 1914 by the company Merck (Parrott et al, 2001), has become a popular recreational drug among young people, particularly in the club culture (eg Green et al, 1995, 2003;

*Correspondence: Dr J-C Cassel, Laboratoire de Neurosciences Comportementales et Cognitives, LN2C, UMR 7521, CNRS/Université Louis Pasteur, GDR 2905 CNRS, IFR 37 Neurosciences, 12 rue Goethe, Strasbourg F-67000, France, Tel: + 33390 24l 952, Fax: + 33390241958 ,

E-mail: jean-christophe.cassel@psycho-ulp.u-strasbg.fr

Received 29 November 2004; revised 26 January 2005; accepted 31 January 2005

Online publication: 8 February 2005 at http://www.acnp.org/citations/ NPP020805040554/default.pdf
Schifano, 2004). Acutely, MDMA causes a rapid release of serotonin (5-HT) and dopamine (DA) in the brain. This increase is accompanied by, and is most likely responsible for, the dose-dependent increase in spontaneous activity in humans and rodents. In addition, MDMA produces hyperthermia that can be fatal in rodents, primates, and humans (Schifano, 2004). Chronic administration of high doses of MDMA may result in depletion of 5-HT and 5hydroxyindoleacetic acid (5-HIAA) in brain regions such as the hippocampus, cortex, and striatum (Green et al, 2003). In rats, the magnitude and duration of this decrease may depend on various factors such as dose, number and frequency of treatments, and genetically based individual differences in sensitivity (Green et al, 2003).

In humans, MDMA is frequently taken with other drugs such as amphetamine, cocaine, cannabis, and ethanol. Such combinations presumably enhance the subjective effects of 
the drug (eg Hernandez-Lopez et al, 2002; Lora-Tamayo et al, 2004; Pedersen and Skrondal, 1999; Schifano, 2004), both pharmacodynamically and pharmacokinetically (Oesterheld et al, 2004). Owing to its social role and easy availability, ethanol is frequently taken in combination with MDMA (eg Lora-Tamayo et al, 2004; Pedersen and Skrondal, 1999; Schifano, 2004).

In a recent series of experiments in rats (Cassel et al, 2004), we found that ethanol dramatically potentiated MDMA-induced hyperlocomotor effect. In contrast, ethanol prevented the hyperpyretic effect of MDMA, at least acutely. Our findings on the effect of the combination on body temperature are in line with data reported by Johnson et al (2004). These authors found that the combination of ethanol and MDMA resulted in a decrease in body temperature higher than that observed after administration of alcohol alone. There are also two studies that address the interaction between MDMA and ethanol in humans. One study focused on the immune system (Pacifici et al, 2001), and the other, on psychomotor performance and subjective effects (Hernandez-Lopez et al, 2002). Interestingly, in the latter study, the authors reported longer lasting euphoria and feelings of well being with combined MDMA and alcohol, compared to either drug alone, suggesting that potentiating effects can be perceived subjectively. In all of these experiments, however, only acute effects of the combination were investigated.

Considering the toxicity of MDMA for serotonergic neurons in some species, and the frequent coadministration of MDMA with other recreational drugs in humans, we were interested in characterizing possible long-term consequences of repeated coadministration of the drugs at short intervals. Along this line, Clemens et al (2004) recently reported that, in rats, MDMA and methamphetamine administered in combination produced greater adverse long-term effects on anxiety and resulted in larger dopaminergic toxicity than either drug alone. Conversely, Morley et al (2004) found that $\Delta^{9}$-tetrahydrocannabinol was able to prevent the acute MDMA-induced hyperthermia, and interestingly, also to exert partial protection against the long-term depletion of 5-HT in various brain regions. In another recent article, Johnson et al (2004) showed that, in mice, coadministration of ethanol with MDMA resulted in a four-fold increase in the concentration of MDMA in the striatum, suggesting that ethanol facilitated MDMA entry into the brain or, alternatively, reduced either the excretion or the biotransformation of this drug. Interestingly, in the same study, ethanol was also found to protect dopaminergic neurons from the toxic effects of MDMA.

In the present study, which was carried out in rats (a species in which MDMA has no reported dopaminergic toxicity; Green et al, 2003), we investigated behavioral, neurochemical, and neuropharmacological effects of repeated treatment with MDMA and ethanol. On 4 consecutive days, male Long-Evans rats were treated with $10 \mathrm{mg} / \mathrm{kg}$ MDMA combined or not with $1.5 \mathrm{~g} / \mathrm{kg}$ ethanol. Behavioral testing was performed between 4 and 19 days after the last injection of the drugs, using T-maze, beam walking, and elevated plus-maze tests. These tests were chosen because (i) T-maze alternation was previously used to assess long-term effects of MDMA (Ricaurte et al, 1993), (ii) in previous experiments, we found that rats with serotonergic lesions exhibited impaired locomotor coordination in the beam-walking task (Lehmann et al, 2000), and (iii) acutely, MDMA is anxiogenic (Sumnall et al, 2004) and anxiety-like behavior can be evidenced weeks, and even months after repeated MDMA injections (eg Bull et al, 2004; Clemens et al, 2004; McGregor et al, 2003). After behavioral testing (ie about 3 weeks after the end of treatment), the rats were killed for examination of 5-HT and catecholamine function (determination of monoamine concentrations and transmitter release experiments in brain slices).

\section{MATERIALS AND METHODS}

\section{Subjects}

In all, 72 adult male Long-Evans rats (3 months; Centre d'Elevage R Janvier, Le Genest-St-Isles, France) were used. They were housed individually in transparent Makrolon cages $\left(42 \times 26 \times 15 \mathrm{~cm}^{3}\right)$ under controlled temperature $\left(23^{\circ} \mathrm{C}\right)$ and a $12 / 12 \mathrm{~h} \mathrm{light/dark}$ cycle (lights on at 0700$)$. Food and water were provided ad libitum. After arrival in the laboratory, the animals were allowed to acclimate to the laboratory for 1 week before the experiments were started. All experimental procedures were conducted in conformity with the institutional guidelines (council directive 87848, October 19, 1987, Ministère de l'Agriculture et de la Forêt, Service Vétérinaire de la Santé et de la Protection Animale; permission 6212 to J-CC and 6714-bis to $\mathrm{HJ}$; $\mathrm{NIH}$ publication, 86-23, revised 1985).

\section{Drugs and Treatment Protocols}

Ethanol $(20 \%(\mathrm{w} / \mathrm{v}))$ was prepared from absolute ethanol diluted in $0.9 \% \mathrm{NaCl}$ and injected intraperitoneally (i.p.) at a dose of $1.5 \mathrm{~g} / \mathrm{kg}$. At this dose, ethanol typically results in a blood concentration of about $175 \mathrm{mg} / \mathrm{dl}$. MDMA (NIDA, USA) was diluted in $0.9 \% \mathrm{NaCl}$ and injected i.p. at a dose of $10 \mathrm{mg} / \mathrm{kg}$. The drugs, whether administered alone or in combination, were injected at a volume of $7.5 \mathrm{ml} / \mathrm{kg}$. For the combined administration, MDMA was dissolved in the $20 \%$ ethanol solution. On four occasions, $24 \mathrm{~h}$ apart, rats were treated with one of the drugs/combination. The acute pyretic and locomotor responses to these drugs and to their combination have been considered in a recent experiment (Cassel et al, 2004), and were not assessed in the present study, except for body temperature on a randomly selected series of rats (see below).

The chemicals and drugs used for brain slice superfusion experiments were obtained from the following sources: 5$\left[1,2-{ }^{3} \mathrm{H}(\mathrm{N})\right]$ hydroxytryptamine creatinine sulfate $\left(\left[{ }^{3} \mathrm{H}\right] 5\right.$ $\mathrm{HT}, 30.0 \mathrm{Ci} / \mathrm{mmol}$ ) from Perkin-Elmer, Rodgau, Germany; 6-nitroquipazine maleate from RBI, Biotrend, Köln, Germany; methiotepin mesylate from Sigma Aldrich $\mathrm{GmbH}$, Taufkirchen, Germany; and CP 93,129 (3-(1,2,5,6-tetrahydropyrid-4-yl)pyrrollo[3,2-b]pyrid-5-one) was a gift from Dr Pagani, Pfizer Inc., Groton, USA.

\section{Body Temperature Measurements}

Rectal temperature was measured with a Pic indolor Vedo Flex (Artsana-Grandate, Italy) digital thermometer with a $0.1^{\circ} \mathrm{C}$ precision, and lubricated with Vaseline. Determina- 
tion of the temperature took a maximum of $30 \mathrm{~s}$. The first measurement was taken $1 \mathrm{~h}$ before drug treatment (between 1100 and 1120). The other measurements were made 30 , $60,120,180$, and $300 \mathrm{~min}$ after drug administration. The ambient temperature during measurements was of $23 \pm 0.1^{\circ} \mathrm{C}$. Group sizes were: SALINE, $n=5$; EtOH, $n=6$; MDMA, $n=5$; and EtOH + MDMA, $n=7$. The initial size of the MDMA group was 7, but two rats died after MDMA treatment.

\section{Behavioral Evaluations}

Two subgroups of rats from each treatment condition were randomly tested (1) for T-maze alternation and beamwalking performance (SALINE, $n=10 ; \mathrm{EtOH}, n=12$; MDMA, $n=10 ; \mathrm{EtOH}+\mathrm{MDMA}, n=9)$ and (2) elevated plus maze (SALINE, $n=7$; EtOH, $n=8$; MDMA, $n=7$; $\mathrm{EtOH}+\mathrm{MDMA}, n=9)$.

Alternation in the T-maze test. Starting 4 days after the last injection, all rats were tested for spontaneous alternation in a T-maze (spontaneous meaning in the absence of any food reward). All testing was conducted between 1200 and 1800 . The apparatus was a gray Perspex $T$ maze $(10 \mathrm{~cm}$ high $\times 10 \mathrm{~cm}$ wide) with a transparent Perspex roof and a $40-\mathrm{W}$ white lamp located $105 \mathrm{~cm}$ above the choice point. The 45-cm-long stem and 21-cm-long side arms ended in 20-cm-long interchangeable start/goal boxes. Guillotine doors were located at the entrance to the stem and on each side arm, thus allowing for the rat to be confined in the start box or in the chosen arm. For each trial, the rat was first subjected to a forced run for which it was placed in the start box for $10 \mathrm{~s}$ before the guillotine door was opened. Once the rat had reached the end of the forced arm (the other arm being closed), it remained in this arm for $30 \mathrm{~s}$ before another run was allowed (with both arms open). Start and goal boxes were interchanged with the rat inside. One trial (one trial consisting in a forced run followed by a test run) was given each day during 4 days, and two additional trials were given on the 5 th day ( $4 \mathrm{~h}$ apart), so that six possible alternations were tested for each rat over the 5-day period. The experimenter was not aware of the rat's previous treatment. The variable considered was the percent alternation on the six trials ((number of alternations/6) $\times 100)$.

Sensory-motor coordination in the beam-walking test. Starting 10 days after the last injection, this test was also conducted between 1200 and 1800. Assessment of motor coordination was performed by placing each rat on a $2 \times 200 \mathrm{~cm}^{2}$ wooden beam, divided into four $50-\mathrm{cm}$ segments, elevated $80 \mathrm{~cm}$ above the floor level, and which was in contact with the home cage on one extremity. All rats were trained according to the following protocol: in the first session, the rats were placed on the beam at $50 \mathrm{~cm}$ from the goal box (ie their home cage) on five consecutive occasions. In the next session, the rats were placed at 50,100, 150, and $200 \mathrm{~cm}$ from the goal box, successively, with only one run allowed for each distance. In the third session, the rats were placed twice at $100 \mathrm{~cm}$ and twice at $200 \mathrm{~cm}$ from the goal box. In the fourth session, the rats were placed at $200 \mathrm{~cm}$ for three consecutive runs. On the next day, all rats were tested for three consecutive trials as in the fourth session and their performance was rated. For each virtual $50-\mathrm{cm}$ segment of the beam, the experimenter rated the locomotor behavior a score of one per segment when the rat traversed the segment with all paws on the upper surface of the beam. Conversely, a score of 0 was given for each segment on which the rat slipped or placed its toes on the side surface of the beam. The overall score was calculated by adding the scores of the three runs (maximal score $=12$ ). The observer was not aware of the rat's previous treatment.

Anxiety in the elevated plus-maze test. In the present study, anxiety-like behavior was measured in the elevated plus maze 19 days after the last drug injection. We used conditions under which rats do not normally avoid entering the open arm. Each rat was brought individually to the testing room $45 \mathrm{~min}$ before the test was started and kept in the home cage. The elevated plus-maze apparatus was made of black Plexiglas and consisted of four arms $(50 \mathrm{~cm}$ long $\times 10 \mathrm{~cm}$ wide) fixed to a central platform $\left(10 \times 10 \mathrm{~cm}^{2}\right)$ : two had $40-\mathrm{cm}$ high walls (closed arms) and two had $1.5-\mathrm{cm}$ high borders in place of the walls (open arms). The arms crossed at a right angle and the apparatus was elevated $73 \mathrm{~cm}$ above the floor. The testing room was equipped with four halogen lamps, positioned on the diagonals of the plus maze $\left(45^{\circ}\right.$ from each arm), at an identical distance from the central platform. For both open arms, the intensity of the light was $10 \mathrm{Lx}$. For testing, rats were placed individually in the center of the maze with their head facing a closed arm (the same for all rats). Between each test, the apparatus was wiped clean with a solution of $2.0 \%$ cider vinegar. Each test lasted for $5 \mathrm{~min}$. The measures were taken by an experimenter, blind to the treatments, who observed the rats via a monitor connected to a camera (fixed on the desk, $300 \mathrm{~cm}$ above the floor level). An entry in a given arm was counted when the rat had completely entered the arm (four paws + tail in the arm). The primary measures were the number of entries and the time spent in each arm. Entries and time in the center were also recorded. These measures enabled us to compute the number of entries and time spent on open and in closed arms, respectively. To balance for potential locomotion biases, the absolute number of entries and time on the open arms was expressed as a percentage of the total number of entries in all arms or of the time spent in these arms, respectively (open/(closed + open $) \times 100)$.

\section{Neurochemical Determinations}

Tissue preparation. At 20 days after the last injection, some of the rats from each group of rats tested for spontaneous alternation and beam walking (SALINE: $n=8$; EtOH: $n=10$; MDMA: $n=8$; EtOH + MDMA: $n=7)$ were killed by microwave irradiation $(1.5 \mathrm{~s} ; 6.3 \mathrm{~kW}$; Sairem, Villeurbanne, France) in order to inactivate rapidly brain enzymes. After decapitation, the brain was extracted and dissected on a cold plate in order to extract the prefrontal, frontal, temporal and occipital cortices, the striatum, the septum, and both hippocampi, which were separated into a dorsal (septal pole) and a ventral (temporal pole) portion. The left and right structures from each rat were pooled, weighed, and kept at $-80^{\circ} \mathrm{C}$ until neurochemical determination. Concentrations of DA, norepinephrine, 5-HT, and 5-HIAA 
were measured using high-performance liquid chromatography (HPLC) with electrochemical detection. The tissue samples were prepared for HPLC by homogenization in $1 \mathrm{~N}$ formic acid/acetone (18/8.5, vol/vol), and the formic extract was used for monoamine determinations.

Determination of monoamine concentrations. The monoamine concentrations were measured without further purification. The HPLC system consisted of an ESA liquid chromatography pump (ESA Inc., Bedford) coupled to an ESA Coulochem II detector (Eurosep Instruments) equipped with a 5014 high-performance analytic cell (ESA Inc., Bedford). The detector potential at the analytic cell was set at $+0.4 \mathrm{~V}$. High-performance liquid chromatography analysis was performed on a C18 Spherisorb ODS2 reversephase column $(5 \mu \mathrm{m}$ pore size, $4.6 \mathrm{~mm}$ in diameter, $25 \mathrm{~cm}$ long). The mobile phase consisted of $0.1 \mathrm{M} \mathrm{NaH} \mathrm{NO}_{4}$, $\mathrm{pH}=3$, containing $0.1 \mathrm{mM} / 1$ of EDTA, $1.7 \mathrm{mM} / 1$ L-octane sulfonic acid sodium salt, and $10 \%$ acetonitrile. The flow rate was $1 \mathrm{ml} / \mathrm{min}$.

\section{5-HT Release}

The rats used for the superfusion experiments were those that were tested in the elevated plus maze. All experiments started about 3 weeks after the last treatment and were conducted within a 3-week period. The rats were killed by decapitation, their brain was quickly removed, and two regions were dissected out from each hemisphere, namely the hippocampus and part of the frontoparietal cortex. Only the dorsal part of both hippocampi and the cortex pieces were used for superfusion experiments. For this purpose, they were cut in slices along the septotemporal and anteroposterior axis, respectively, using a McIIwain tissue chopper. The slices $(350 \mu \mathrm{m})$ were separated and washed three times with a modified Krebs-Henseleit $(\mathrm{KH})$ buffer and incubated in small plastic Petri dishes containing $2 \mathrm{ml}$ of $\mathrm{KH}$ buffer with $\left[{ }^{3} \mathrm{H}\right] 5-\mathrm{HT}(0.1 \mu \mathrm{M})$ for $45 \mathrm{~min}$ at $37^{\circ} \mathrm{C}$ under carbogen. The $\mathrm{KH}$ solution had the following composition (in $\mathrm{mM}$ ): $\mathrm{NaCl}, 118 ; \mathrm{KCl}, 4.8 ; \mathrm{CaCl}_{2}, 1.3$; $\mathrm{MgSO}_{4}, 1.2 ; \mathrm{NaHCO}_{3}, 25 ; \mathrm{KH}_{2} \mathrm{PO}_{4}, 1.2$; glucose, 10; ascorbic acid, 0.6; $\mathrm{Na}_{2} \mathrm{EDTA}, 0.03$; and saturated with carbogen, $\mathrm{pH}$ adjusted to 7.4.

After incubation, the slices from each structure were washed three times with $\mathrm{KH}$ buffer, and transferred into superfusion chambers (one slice per chamber) with a total of 12 chambers for the hippocampus and 12 for the cortex slices (all chambers were identical). As soon as they were in the chambers, the slices were superfused with oxygenated $\mathrm{KH}$ buffer $\left(37^{\circ} \mathrm{C}\right)$ at a rate of $1.2 \mathrm{ml} / \mathrm{min}$. The superfusion buffer was supplemented with 6-nitroquipazine throughout $(1 \mu \mathrm{M})$. After $15 \mathrm{~min}$ of superfusion, the slices were prestimulated by electrical fields (18 rectangular pulses at $3 \mathrm{~Hz}, 2 \mathrm{~ms}, 4 \mathrm{~V} / \mathrm{chamber}, 25-28 \mathrm{~mA}$ ) and, after $32 \mathrm{~min}$, collection of 2-min fractions was started. The release of $\left[{ }^{3} \mathrm{H}\right] 5-\mathrm{HT}$ was induced three times by electrical field stimulations (360 rectangular pulses at $3 \mathrm{~Hz}, 2 \mathrm{~ms}, 4 \mathrm{~V} /$ chamber, $25-28 \mathrm{~mA})$ after $36 \mathrm{~min}\left(S_{1}\right), 52 \mathrm{~min}\left(S_{2}\right)$, and $68 \mathrm{~min}\left(S_{3}\right)$ of superfusion. Drugs to be tested (the $5-\mathrm{HT}_{1 \mathrm{~B}}$ receptor agonist, CP 93,129, at concentrations from 0.001 to $1 \mu \mathrm{M}$, and the mixed $5-\mathrm{HT}_{1 \mathrm{~A}} / 5-\mathrm{HT}_{1 \mathrm{~B}}$ antagonist, methiotepin, at concentrations of 0.1 and $1 \mu \mathrm{M}$ ) were added to the superfusion medium from 8 min before $S_{2}$ and $S_{3}$ onwards, with concentrations increasing from $S_{2}$ to $S_{3}$. At the end of the experiment (ie after $76 \mathrm{~min}$ of superfusion), the radioactivity of superfusate samples and slices (dissolved in $300 \mu \mathrm{l}$ Solvable 350, Perkin-Elmer, Rodgau, Germany) was determined by liquid scintillation counting.

The tritium outflow was calculated as a fraction of the tritium content in the slice at the onset of the corresponding collection period (fractional rate). The basal tritium outflow in the fraction preceding $S_{1}$ is given either in absolute terms (nCi $\left[{ }^{3} \mathrm{H}\right]$ outflow per $2 \mathrm{~min}$ ) or in relative terms (fractional rate of $\left[{ }^{3} \mathrm{H}\right]$ outflow per $2 \mathrm{~min}$ ). The stimulation-evoked overflow of tritium was calculated by subtraction of the basal outflow and is shown either in absolute terms ( $\mathrm{nCi}$ $\left[{ }^{3} \mathrm{H}\right]$ overflow) or in relative terms (in percent of the tritium content of the slice at the onset of the respective stimulation period). Effects of drugs added before $S_{2}$ and $S_{3}$ were determined as the ratio of the overflow evoked by the corresponding stimulation period $\left(S_{2} / S_{1}\right.$ or $\left.S_{3} / S_{1}\right)$ and compared to the appropriate control ratios (no drug addition before $S_{2}$ or $S_{3}$, respectively).

\section{Statistical Analyses}

All data were analyzed using analyses of variance (ANOVA). Where appropriate, ANOVA was followed by pair-wise comparisons using the Newman-Keuls test (Winer, 1971). It should be noticed that the significant differences between MDMA and EtOH rats, which lack on relevance, are not indicated in the text or the figures. For statistical evaluation of transmitter release experiments, only the mean values calculated from up to 12 'slice values' for each individual rat were used in the ANOVA. Two rats initially included in this series of experiments died during temperature measurements. From each group of rats tested for spontaneous alternation and beam walking, two rats were not killed.

\section{RESULTS}

\section{Acute Effects of MDMA on Body Temperature}

Whatever day was considered, $1 \mathrm{~h}$ before drugs/combination administration, the average body temperature did not significantly vary among groups (Day 1: $37.9 \pm 0.1$; Day 2: $37.5 \pm 0.1$; Day 3: $37.7 \pm 0.1$; Day 4: $37.4 \pm 0.1$, in ${ }^{\circ} \mathrm{C}$ ). The other data are shown in Figure 1. Treatment (SALINE, EtOH, MDMA, EtOH + MDMA) $\times$ Time $(30,60,120,180$, and $300 \mathrm{~min}$ after injection) $\times$ Day (days $1,2,3$, and 4 ) ANOVA showed all factors and interactions to be significant. The Treatment effect ( $\mathrm{F} 3 / 19=15.7, p<0.001)$ was due to a temperature increase in MDMA and $\mathrm{EtOH}+$ MDMA rats $(p<0.001)$. The Time effect (F $4 / 76=15.2$, $p<0.001)$ was due to temperatures that were significantly higher, mainly 60,120 , and 180 min after treatment, with the highest level achieved at $60 \mathrm{~min}(p<0.05$ at least). The Day effect was due to body temperatures that were significantly higher on day 1 or day 2 as compared to the subsequent ones $(p<0.05)$. Treatment $\times$ Time interaction can be explained by the peak that was observed at the postinjection delay of $60 \mathrm{~min}$ in MDMA and EtOH + MDMA rats. The Treatment $\times$ Day interaction is due to the temperature fluctuations in MDMA and EtOH + MDMA rats. The 


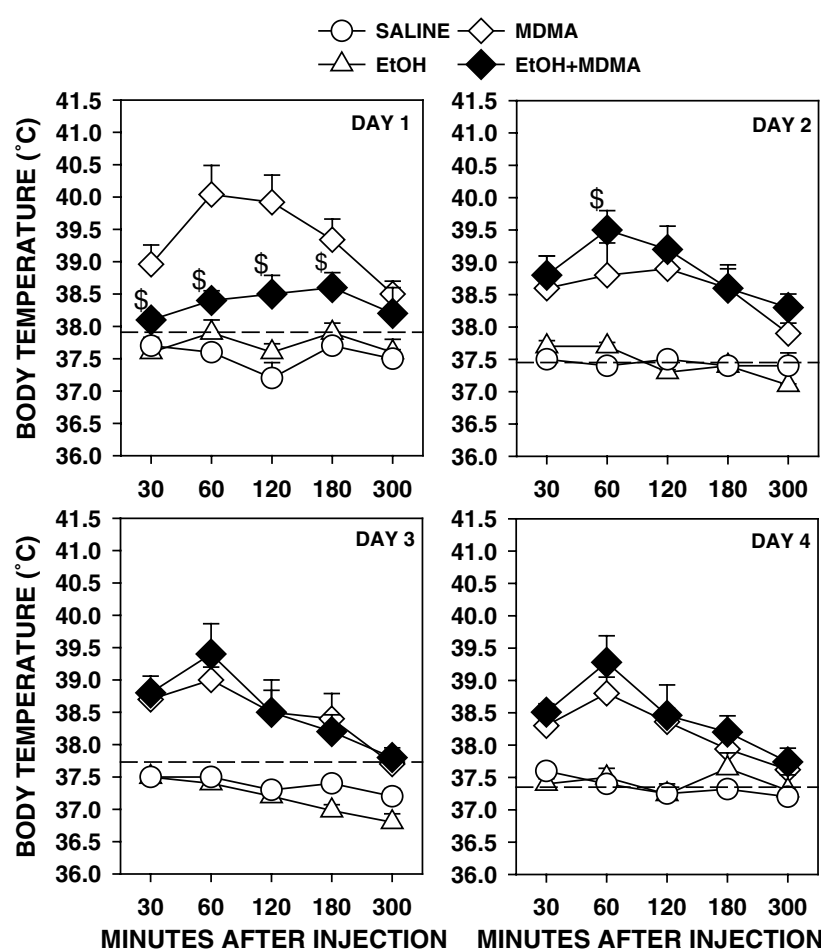

Figure I Mean body temperature (mean + SEM) at five delays $(30,60$, 120, I80, and $300 \mathrm{~min}$ ) after injections of saline (SALINE; injection volume $7.5 \mathrm{ml} / \mathrm{kg}$ ), ethanol ( $\mathrm{EtOH}$; daily dose of $1.5 \mathrm{~g} / \mathrm{kg}),( \pm)$-3,4-methylenedioxymethamphetamine (MDMA; daily dose of $10 \mathrm{mg} / \mathrm{kg}$ ), or both EtOH and MDMA (EtOH + MDMA; daily dose $1.5 \mathrm{~g} / \mathrm{kg}$ and $10 \mathrm{mg} / \mathrm{kg}$, respectively). In each panel, the dashed line indicates the average body temperature of all rats measured $60 \mathrm{~min}$ before treatment administration (SEM was approximately $0.1^{\circ} \mathrm{C}$ ). Injections were made on four consecutive days ( $1-4$, respectively). To prevent an overload of statistical symbols in the figure, only significant differences between MDMA and EtOH + MDMA rats are indicated: ${ }^{\$} p<0.05$. On all 4 days, the temperature in MDMA and $\mathrm{EtOH}+\mathrm{MDMA}$ rats was significantly higher than that measured in SALINE or EtOH rats. The difference between overall temperatures in SALINE and $\mathrm{EtOH}$ rats was not significant.

Time $\times$ Day interaction can be explained by the fact that, on the longest postinjection delays, the overall temperature reached weaker values on the last 2 days as compared to the first two ones. Part of the Treatment $\times$ Time $\times$ Day interaction is due to a temperature that, on day 1 , was significantly higher in MDMA rats as compared to EtOH + MDMA rats on time points $1(p<0.05), 2(p<0.001), 3(p<0.05)$, and $4(p<0.05)$, not 5 . This difference was not observed on the subsequent days. Also, on time point 2 of day 2, the temperature was significantly higher in EtOH + MDMA rats as compared to MDMA rats $(p<0.05)$.

In summary, MDMA-induced hyperthermia was partly prevented by ethanol coadministration, but only after the first treatment.

\section{Behavioral Data}

T-maze alternation. There was no effect of treatment on this behavioral measure (data not shown). The average alternation rates were $74.0 \pm 5.2$ (SALINE), $73.3 \pm 8.3$ $(\mathrm{EtOH}), \quad 80.0 \pm 5.2 \quad$ (MDMA), and $66.7 \pm 9.4 \quad(\mathrm{EtOH}+$ MDMA).

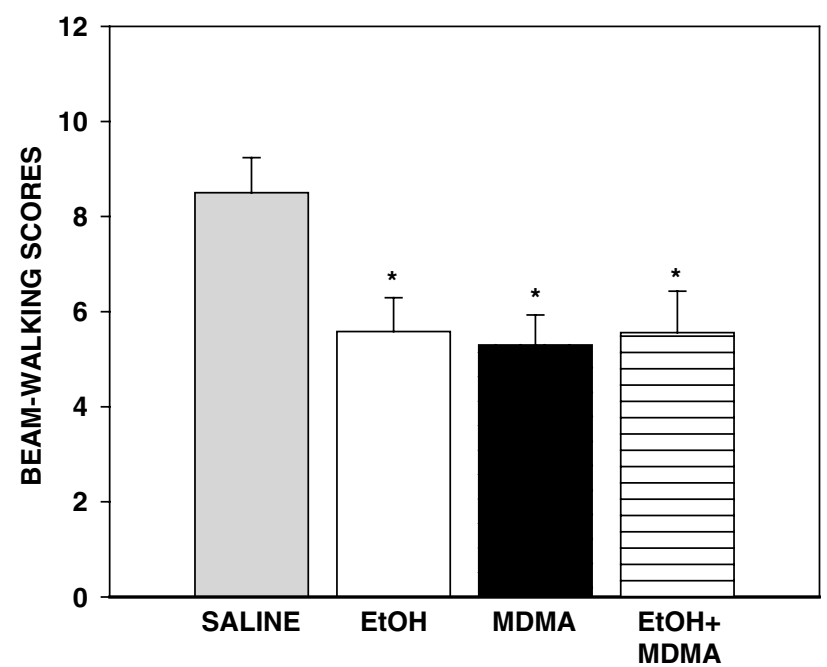

Figure 2 Beam-walking scores (mean + SEM; maximal score =12) in the four groups of rats. Group abbreviations as in Figure I. *Significantly different from SALINE, $p<0.05$.

Beam walking. The results are shown in Figure 2. ANOVA showed an overall Treatment effect (F 3/37 $=4.1, p<0.05)$. Multiple comparisons showed that the beam-walking scores were significantly lower in $\mathrm{EtOH}, \mathrm{MDMA}$, and $\mathrm{EtOH}+$ MDMA rats as compared to control $(p<0.05)$. The means among the three drug treatment groups were not significantly different from each other.

Elevated plus maze. ANOVA of the number of arm entries failed to show a significant Treatment effect (F $3 / 27<1.0$; score in SALINE was $20.6 \pm 1.4$ ). ANOVA also failed to show a significant Treatment effect on other variables (percent entries in open arms, F $3 / 27<1.0$; score in SALINE was $43.2 \pm 3.2$; percent time on open arms, F $3 / 27<1.0$; score in SALINE was $34.4 \pm 5.5)$. Data are not illustrated.

\section{Neurochemical Data}

Norepinephrine concentration. The data are presented in Table 1. In none of the brain regions did we observe a significant effect of Treatment. There was a trend, however, seen in the frontal cortex $(\mathrm{F} 3 / 29=2.37, p<0.1)$.

DA concentration. Mean concentrations are presented in Table 1. ANOVA showed a significant Treatment effect in the striatum $(\mathrm{F} 3 / 29=3.1, p<0.05)$ and the temporal cortex (F $3 / 29=3.8, p<0.01)$. In the striatum, DA concentration was significantly less in EtOH + MDMA as compared to MDMA rats $(p<0.05)$. In EtOH + MDMA rats, the DA concentration also tended to be less than in saline-treated rats $(p=0.08)$. In the temporal cortex, the DA concentration was significantly greater in EtOH + MDMA rats as compared to the EtOH rats $(p<0.05)$, and tended to be greater than in MDMA rats $(p=0.08)$. In the other regions, there was no significant Treatment effect.

DOPAC concentration. The data are shown in Table 1. ANOVA showed a significant Treatment effect in the temporal cortex (F $3 / 29=3.4, p<0.05)$ and in the ventral hippocampus $(\mathrm{F} 3 / 29=4.2, p<0.05)$. In the temporal 
Table I Concentration of Catecholamines in the Different Brain Structures of SALINE, EtOH, MDMA, and EtOH+MDMA Rats (All Values Correspond to Means \pm SEM and are Given in $\mathrm{pg} / \mathrm{mg}$ Irradiated Tissue)

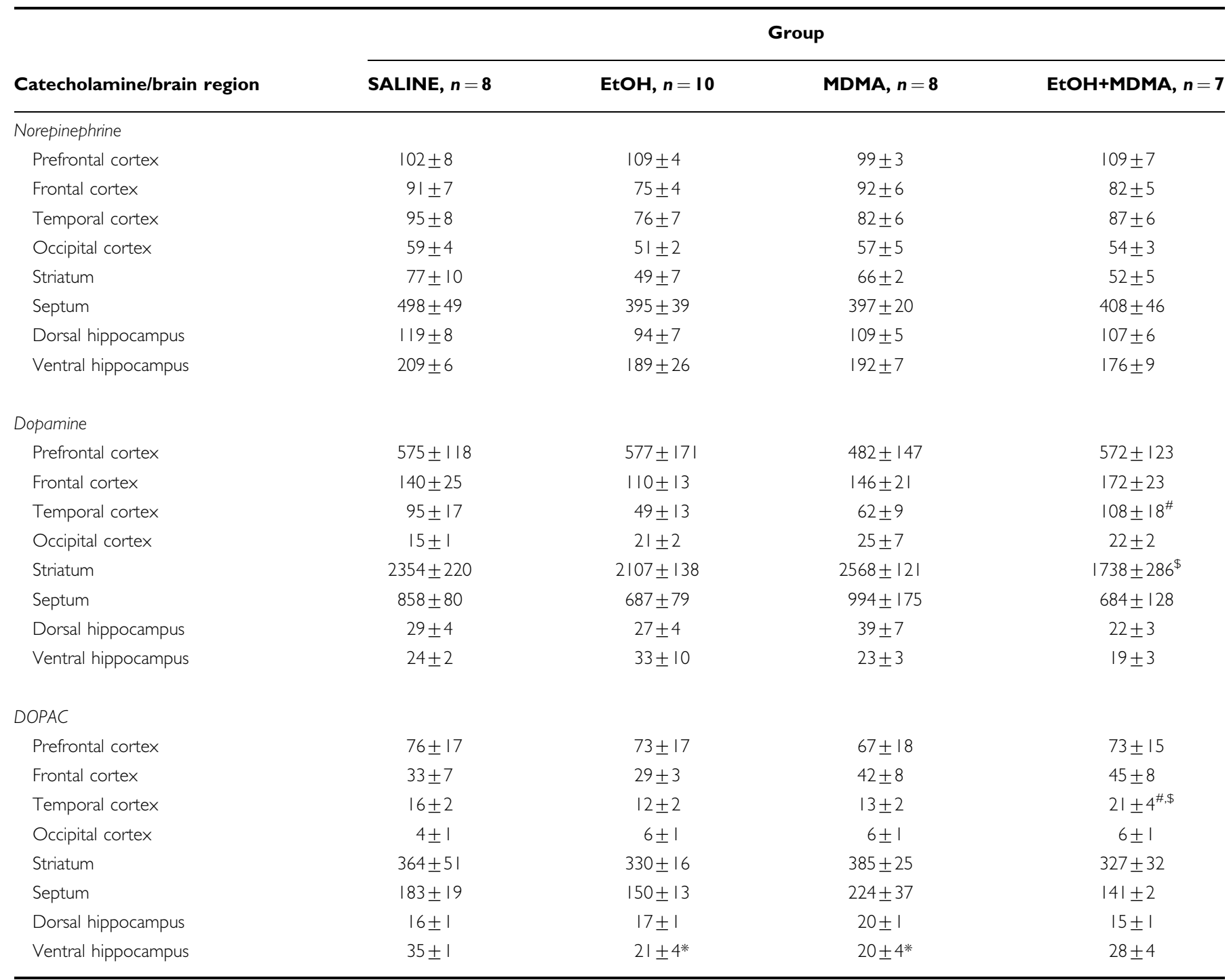

*Significantly different from SALINE, $p<0.05$.

\#Significantly different from $\mathrm{EtOH}, p<0.05$.

\$Significantly different from MDMA.

cortex, the concentration of DOPAC was significantly elevated in $\mathrm{EtOH}+\mathrm{MDMA}$ rats as compared to $\mathrm{EtOH}$ or MDMA rats $(p<0.05$ in each case). In the ventral hippocampus, the concentration of DOPAC was significantly reduced in EtOH and MDMA rats as compared to their saline-treated counterparts $(p<0.05$ in each case). In the other regions, there was no significant Treatment effect.

5-HT concentration. The reader is directed to Figure 3. The concentration of 5-HT was significantly affected in all regions $(\mathrm{F} 3 / 29=4.5, p<0.01$ or less). In the prefrontal cortex, the concentration of 5-HT was significantly reduced in EtOH + MDMA rats as compared to EtOH $(p<0.01)$; in $\mathrm{EtOH}$ rats, the 5-HT concentration was also significantly higher than in SALINE rats $(p<0.05)$. In the three other cortical regions (frontal, temporal, occipital), the 5-HT concentration was significantly lower in MDMA and $\mathrm{EtOH}$
+ MDMA rats as compared to SALINE rats $(p<0.05)$, and in EtOH + MDMA rats as compared to MDMA $(p<0.05)$. In the striatum, a significant reduction of the 5-HT concentration was found in MDMA and EtOH + MDMA rats as compared to SALINE rats $(p<0.001$ in each case). In the septal region, the concentration of $5-\mathrm{HT}$ was significantly lower in $\mathrm{EtOH}+\mathrm{MDMA}$ rats as compared to EtOH or SALINE rats $(p<0.01)$; in MDMA rats, the reduction was also significant $(p<0.05)$. Finally, in the dorsal hippocampus, the concentration of 5-HT was significantly less in MDMA and EtOH + MDMA rats as compared to SALINE rats $(p<0.01$ at least); in the ventral hippocampus, there was a similar picture.

5-HIAA concentration. Data are shown in Figure 3. As the overall profile of 5-HIAA levels was very comparable to that of 5-HT levels, results are not described in detail. 

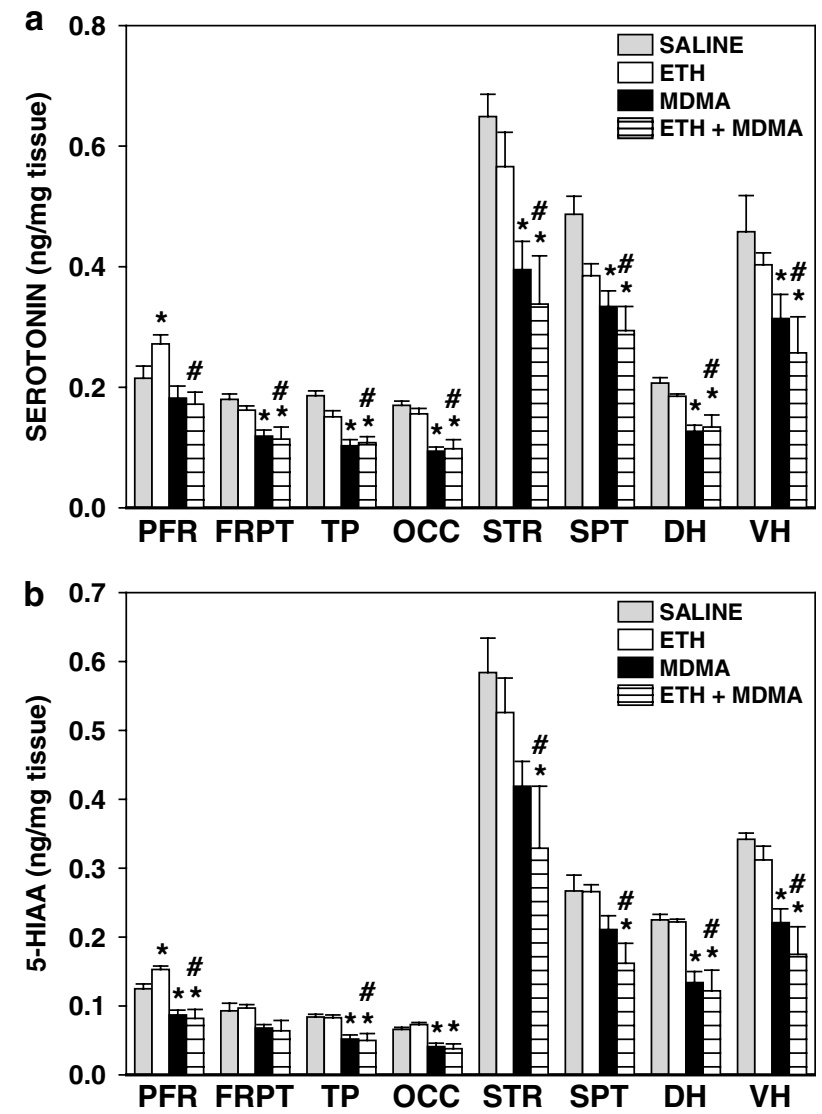

Figure 3 Concentration (mean + SEM) of 5-HT (a) and 5-HIAA (b) in various regions of the cortex (PFR: prefrontal; FRPT: frontoparietal; TP: temporal; OCC: occipital) and other brain regions (STR: striatum; SPT: septum; DH: dorsal hippocampus; $\mathrm{VH}$ : ventral hippocampus) in the four groups of rats. Group abbreviations as in Figure I. *Significantly different from SALINE, $p<0.05$; ${ }^{\#}$ significantly different from $\mathrm{EtOH}, p<0.05$.
5-HIAA/5-HT ratio. These data are not illustrated. ANOVA showed a significant Treatment effect on the 5-HIAA/5-HT ratio only in the septal region and in the dorsal hippocampus (F $3 / 29=3.0$ and 8.8 , respectively, $p<0.05$ ). In the septal region, multiple comparisons failed to show any significant difference between two conditions: the ratio tended to be smaller in EtOH + MDMA rats as compared to $\mathrm{EtOH}$ rats and larger in EtOH rats as compared to SALINE ones $(p<0.10)$. In the dorsal hippocampus, the ratio was significantly smaller in EtOH + MDMA rats as compared to each of the three other groups ( $p<0.05$ at least). In MDMA rats, this ratio was also significantly smaller than in EtOH rats $(p<0.05)$.

\section{5-HT Release}

Accumulation of $\left[{ }^{3} \mathrm{H}\right]-5-\mathrm{HT}$ by cortical and hippocampal slices. Data are shown in Table 2. ANOVA of the $\left[{ }^{3} \mathrm{H}\right] 5-\mathrm{HT}$ accumulation showed no significant Treatment effect, whether in the cortex $(\mathrm{F} 2 / 27<1.0)$ or the hippocampus (F $3 / 27<1.0)$.

Baseline outflow of tritium in cortical and hippocampal slices. Data are presented in Table 2. ANOVA of baseline outflow of tritium from cortical or hippocampal slices showed no significant Treatment effect on absolute (nCi) or the relative (percent of accumulated $\left[{ }^{3} \mathrm{H}\right]$ ) outflow (F 3/27 always lower than $2.2, p>0.10$ ).

Electrically evoked overflow of tritium in cortical and hippocampal slices. The data are shown in Table 2. ANOVA of the electrically evoked release from cortical slices showed a significant Treatment effect on absolute values (F $3 / 27=3.69, p<0.05$ ), but not on relative ones (F $3 / 27=2.1)$. This Treatment effect was due to significantly

Table 2 Accumulation of $\left.{ }^{3} \mathrm{H}\right] 5-\mathrm{HT}$, Basal Outflow and Electrically Evoked Overflow of Tritium in Cortical and Hippocampal Slices from SALINE, EtOH, MDMA and EtOH+MDMA Rats (All Values are Means \pm SEM Outflow and Overflow are Indicated in Absolute Values or as a Percentage of the Tritium Accumulated in Each Slice)

Group

\begin{tabular}{|c|c|c|c|c|}
\hline \multirow[b]{2}{*}{ Brain region/variable } & & & & \\
\hline & SALINE, $n=7$ & EtOH, $n=8$ & MDMA, $n=7$ & EtOH+MDMA, $n=9$ \\
\hline$\left[{ }^{3} \mathrm{H}\right] 5-\mathrm{HT}$ accumulation (pmol/slice) & $0.634 \pm 0.03$ & $0.646 \pm 0.04$ & $0.690 \pm 0.03$ & $0.697 \pm 0.03$ \\
\hline Baseline $\left[{ }^{3} \mathrm{H}\right] 5-\mathrm{HT}$ outflow in $\%$ of $\left[{ }^{3} \mathrm{H}\right]$ accumulation & $2.360 \pm 0.16$ & $2.220 \pm 0.11$ & $2.146 \pm 0.06$ & $2.192 \pm 0.08$ \\
\hline Electrically evoked $\left[{ }^{3} \mathrm{H}\right] 5-\mathrm{HT}$ outflow (nCi) & $0.756 \pm 0.03$ & $0.899 \pm 0.06$ & $0.982 \pm 0.09 *$ & $1.043 \pm 0.07 *$ \\
\hline \multicolumn{5}{|l|}{ Hippocampus } \\
\hline$\left[{ }^{3} \mathrm{H}\right] 5-\mathrm{HT}$ accumulation (pmol/slice) & $0.779 \pm 0.06$ & $0.813 \pm 0.06$ & $0.761 \pm 0.02$ & $0.730 \pm 0.05$ \\
\hline Baseline $\left[{ }^{3} \mathrm{H}\right] 5-\mathrm{HT}$ outflow (nCi) & $0.456 \pm 0.03$ & $0.509 \pm 0.04$ & $0.421 \pm 0.02$ & $0.420 \pm 0.02$ \\
\hline Baseline $\left[{ }^{3} \mathrm{H}\right] 5-\mathrm{H} T$ outflow in $\%$ of $\left[{ }^{3} \mathrm{H}\right]$ accumulation & $2.022 \pm 0.06$ & $2.139 \pm 0.06$ & $1.902 \pm 0.05$ & $2.055 \pm 0.07$ \\
\hline Electrically evoked $\left[{ }^{3} \mathrm{H}\right] 5-\mathrm{HT}$ outflow (nCi) & $1.033 \pm 0.09$ & $1.002 \pm 0.07$ & $1.043 \pm 0.03$ & $1.124 \pm 0.06$ \\
\hline
\end{tabular}

*Significantly different from SALINE, $p<0.05$.

\#Significantly different from EtOH, $p<0.05$.

\$Significantly different from MDMA, $p<0.05$. 
larger evoked release in MDMA and EtOH + MDMA rats as compared to SALINE rats $(p<0.05)$. In the hippocampus, there was a significant Treatment effect on the relative (F $3 / 27=8.2, p<0.001)$, but not on absolute release (F $3 / 27$ $<1.0)$. This effect was due to a significantly larger relative release in EtOH + MDMA rats as compared to SALINE $(p<0.01)$, EtOH $(p<0.001)$, and MDMA $(p<0.05)$ rats.
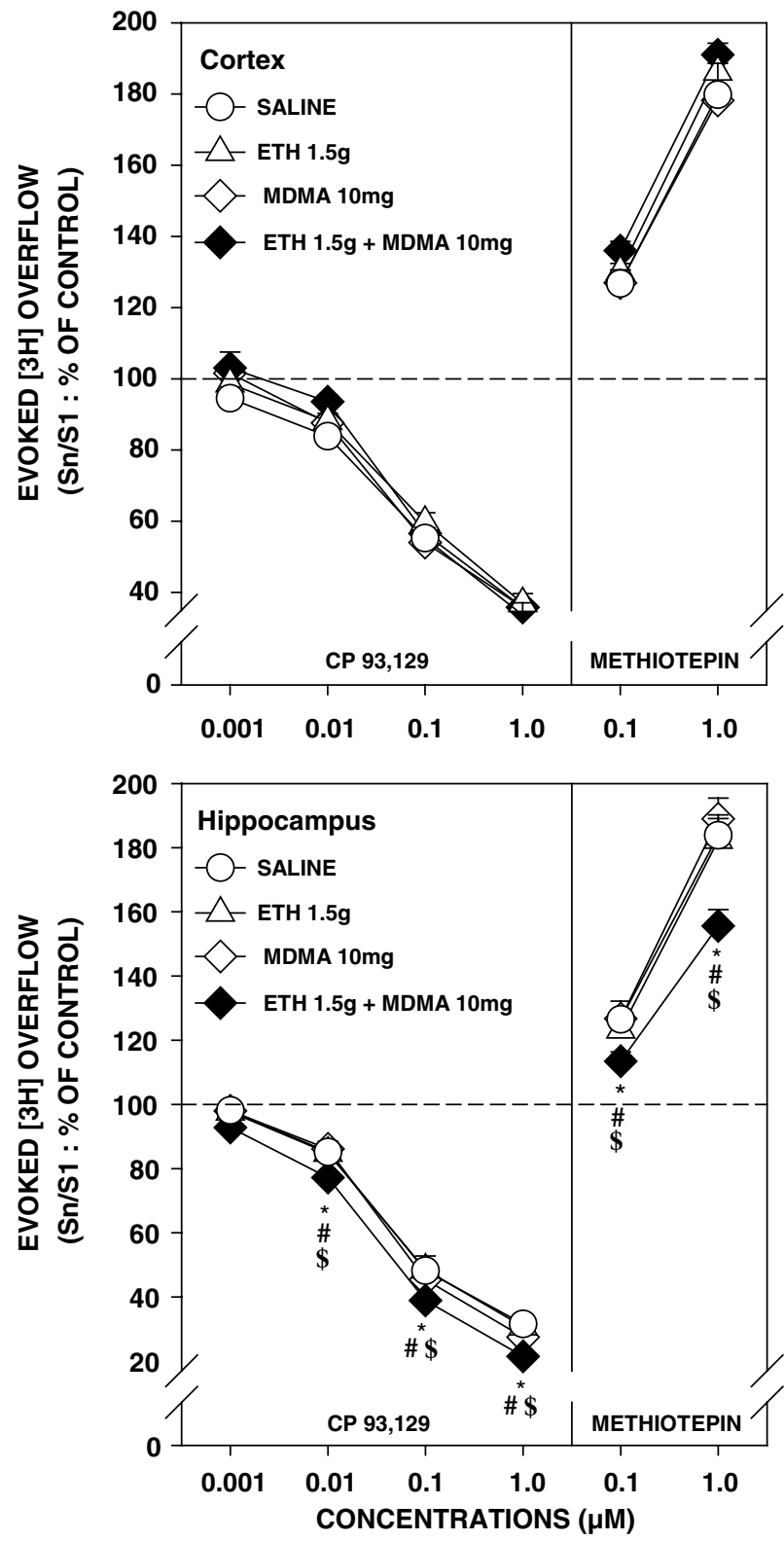

Figure 4 Effects of the autoreceptor agonist CP 93,129 (left panel) or the nonselective $5-\mathrm{HT}$, receptor antagonist methiotepin (right panel) on the electrically evoked release of $\left.{ }^{3} \mathrm{H}\right] 5-\mathrm{HT}$ in cortical (top) and hippocampal (bottom) slices from rats of the four groups. Group abbreviations as in Figure I. Data are the mean (+SEM) evoked overflow expressed as a ratio $\left(S_{n} / S_{1}\right)$, and subsequently normalized for each concentration $(0.00 \mathrm{I}-\mathrm{I} .0 \mu \mathrm{M})$ by computing the percent of control values (no drug added to the superfusate). The dashed lines indicate the control level (no change of the release). The inhibition of the evoked release was significant for concentrations of $0.0 \mathrm{I}$ to $1.0 \mu \mathrm{M}$ in both the cortex and the hippocampus. *Significantly different from SALINE, $p<0.05$; ${ }^{*}$ significantly different from $\mathrm{EtOH}, p<0.05$; ${ }^{\$}$ significantly different from MDMA, $p<0.05$.
Effects of CP 93,129 in cortical and hippocampal slices. Data are shown in Figure 4. In cortical slices, ANOVA showed no significant overall Treatment effect (F 3/27 $=$ 1.9). There was a significant Concentration effect (F $3 / 81=$ $1105.2, p<0.001)$. The interaction between both factors tended to be significant ( $\mathrm{F} 9 / 81=1.9, p=0.06$ ). The Concentration effect can be explained by a concentrationdependent decrease of the release. The release was significantly larger in MDMA and EtOH + MDMA rats than in SALINE rats $(p<0.05$ in each case $)$ at the concentration of $0.001 \mu \mathrm{M}$, and in EtOH + MDMA rats at the concentration of $0.01 \mu \mathrm{M}(p<0.01)$.

In hippocampal slices, ANOVA showed significant effects of Treatment $(\mathrm{F} 3 / 27=7.6, p<0.001)$ and Concentration (F $3 / 81=999.5, p<0.001$ ), but not the interaction (F 9/81 $<1.0$ ). The Treatment effect was due to inhibitory effects of CP-93,129 on 5-HT release that were significantly more pronounced in EtOH + MDMA rats than in the other ones $(p<0.05)$. The Concentration effect can be explained by a concentration-dependent decrease of the release. Multiple comparisons showed that the release in $\mathrm{EtOH}+$ MDMA rats was significantly lower than in each of the three other groups ( $p<0.05$ at least), regardless of the concentration.

Effects of methiotepin in cortical and hippocampal slices. Data are shown in Figure 4. In cortical slices, ANOVA showed no significant overall Treatment effect (F 3/27 = 1.6). There was a significant concentration effect (F $1 / 27=$ $388.7, p<0.001)$, but no interaction (F $3 / 27<1.0)$. At the low concentration of methiotepin, the overall release was increased by about $30 \%$ as compared to control, whereas at the highest one, it was increased by $83 \%$.

In hippocampal slices, ANOVA showed significant Treatment $(\mathrm{F} 3 / 27=5.7, p<0.01)$, Concentration $(\mathrm{F} 1 / 27=580.2$, $p<0.001)$, and interaction ( $\mathrm{F} 3 / 27=4.2, p<0.05)$ effects. The Treatment effect was due to the facilitatory effect of methiotepin, which was smaller in EtOH + MDMA rats than in the rats from the other groups $(p<0.05)$. The Concentration effect was due to a larger increase at the highest concentration $(+78 \%)$. Multiple comparisons showed that for each concentration, the release in EtOH + MDMA rats was significantly lower than in the other groups $(p<0.05)$.

\section{DISCUSSION}

The present results confirm that repeated MDMA intoxication induces alterations in 5-HT and 5-HIAA content in most brain regions assessed. They also demonstrate that combination of ethanol and MDMA does not result in behavioral or neurochemical effects different from those of MDMA alone. The only behavioral alteration found was on beam-walking performance when rats had been given ethanol and/or MDMA, with no additive or synergistic effects between both drugs. At 3-6 weeks after the combined treatment with ethanol and MDMA, lasting changes in the hippocampal modulation of 5-HT release were evident: in the presence of CP 93,129 or methiotepin, the evoked tritium release was significantly lower in EtOH + MDMA rats. To our knowledge, this is the first demonstration that several weeks after its administration, the combination of MDMA with ethanol alters the possibly autoreceptor- 
mediated modulation of 5-HT release in the rat hippocampus, without producing overt serotonergic toxicity or behavioral changes compared to those found after MDMA alone.

\section{Acute Effects of EtOH and/or MDMA Intoxications}

We recently reported that MDMA-induced hyperactivity and hyperthermia (Cassel et al, 2004) did not change in magnitude when the treatment was repeated at three other occasions, $24 \mathrm{~h}$ apart. Furthermore, ethanol treatment had no effect on activity scores, but resulted in a small but significant hypothermia (about $-0.5^{\circ} \mathrm{C}$ ) that showed some tolerance on subsequent days. When coadministered with MDMA, ethanol potentiated the locomotor response and protected against hyperthermia. Prevention of hyperthermia, however, was observed only after the first treatment, as in the present experiment. This limited prevention might have resulted from: (1) tolerance to the hyperthermic effects of MDMA (Marston et al, 1999) or (2) tolerance to the effect of ethanol, perhaps specifically in the presence of MDMA. The pharmacokinetic and/or pharmacodynamic mechanisms underlying these ethanol-induced effects remain as yet unknown. In mice given ethanol and MDMA, the striatal concentration of MDMA was about four times larger than in controls, suggesting that ethanol may interfere with (i) MDMA metabolism, (ii) penetration of MDMA into the brain, or (iii) removal of MDMA from the brain (Johnson et al, 2004). Should the same be true in rats, and as the effects of ethanol on the locomotor (Cassel et al, 2004); (see also Rezvani et al, 1992) and pyretic consequences of MDMA were in opposite directions, one pharmacokinetic explanation could be that MDMA (or a particular metabolite) was involved in one of the effects (hyperlocomotion), while a metabolite (or a further metabolite) would be involved in the other one (hyperthermia). Dissociation between the effects of MDMA and its metabolites has not been demonstrated for behavioral or physiological variables, but were described for toxicity vs 5-HT release. Indeed, direct injection of MDMA into the hippocampus increases 5-HT release without any toxicity to serotonergic terminals (Esteban et al, 2001). Further experiments are needed to understand the mechanism(s) involved in ethanol-induced alterations of MDMA actions.

\section{Long-Term Effects of EtOH and/or MDMA on Monoaminergic Markers}

Now that we have shown that ethanol modulates the acute effects of MDMA, the long-term effects of ethanol-MDMA combinations are of obvious interest, particularly in terms of toxicity. Acute neurochemical and neuropharmacological effects of ethanol are well known, but especially compelling are the consequences after chronic intoxication or during withdrawal (eg Darstein et al, 2000; LeMarquand et al, 1994; Thielen et al, 2004). As to long-term effects of shorter periods of ethanol treatment, however, the literature is, to our knowledge, rather scanty. A few reports show that brief periods of alcohol intoxication (eg binge exposure) may result in damage in the olfactory bulbs, the entorhinal cortex, and the dentate gyrus (Crews et al, 2000; Zou et al, 1996). Recently, Vasconcelos et al (2003) reported that, in rats, ethanol administered daily for 7 days did not alter striatal 5 -HT concentration $48 \mathrm{~h}$ after the last treatment. In the present study, we do not know yet how to account for the significant increase in 5-HT concentration in the prefrontal cortex of rats given only ethanol, but it is interesting to note that in the EtOH and MDMA group, this increase was not observed. Ethanol may interfere with the metabolism of tryptophan (eg Badawy, 1999), as well as alter the sensitivity of presynaptic $5-\mathrm{HT}_{1 \mathrm{~A}}$ receptors (Esteban et al, 2002), and these two findings might be considered consistent with our observations.

Although the serotonergic toxicity of MDMA may vary as a matter of species, strain, and other factors (eg Green et al, 2003), serotonergic alterations are found in rats already 1 week after intoxication (eg Schmidt et al, 1987). These effects persist for several months, despite protracted recovery (Sabol et al, 1996; Scanzello et al, 1993). As our rats were killed 3 weeks after the last drug treatment, recovery of neurochemical parameters was probably limited. Keeping in mind that neurochemical markers are indirect markers of neurotoxicity (Green et al, 2003), and that MDMA toxicity for serotonergic neurons has been recently questioned (Wang et al, 2004, but see Schmued, 2003), our data are in line with reports showing that MDMA reduced 5-HT and 5-HIAA concentrations in several brain regions (Sabol et al, 1996). In addition to changes in the cortex, hippocampus, and striatum, we found serotonergic alterations in the septal region. This finding is at variance with the report by Sabol et al (1996), although in line with the fact that the lateral septum has dense 5-HT innervation (Dinopoulos et al, 1993). The lack of serotonergic effects of MDMA in the prefrontal cortex, another important target of the serotonergic system (eg Steinbusch, 1981), is also surprising. In a recent report, Clemens et al (2004) demonstrated serotonergic toxicity of MDMA in the prefrontal cortex, but only in rats given a high dose $(4 \times 5 \mathrm{mg} / \mathrm{kg} /$ day on 2 successive days $)$. It is also noteworthy that the reduction of serotonergic markers was about $16 \%$ in the prefrontal cortex, but twice that magnitude in brain regions such as the striatum or the hippocampus, suggesting that the serotonergic innervation of the prefrontal cortex might be less sensitive to MDMA toxicity or undergo faster recovery. Against this possibility is the report by McGregor et al (2003), who, 3 months after a high dose of MDMA $(4 \times 5 \mathrm{mg} / \mathrm{kg} / \mathrm{h}$ over $4 \mathrm{~h})$, found that the MDMA-induced decrease of 5-HT concentration was larger in the prefrontal cortex than in the hippocampus. Strain differences (Green et al, 2003) and post-MDMA delays might contribute to such discrepancies between studies. In addition, part of the variability in the MDMA toxicity might also be linked to differential vulnerability/ recovery of projections from the median or dorsal raphé (eg Molliver et al, 1990).

As serotonergic toxicity depends on MDMA-induced hyperthermia (but see McGregor et al, 2003) and alcohol attenuates MDMA-induced hyperthermia (eg Cassel et al, 2004; Johnson et al, 2004), it might seem surprising that serotonergic functioning was similar for MDMA and $\mathrm{EtOH}$ + MDMA-treated rats. One explanation might be that the MDMA-induced hyperthermia was prevented only by the first injection of ethanol, that is, that the similarity in alteration of serotonergic function in MDMA and EtOH + 
MDMA rats can be accounted for by tolerance to ethanol in its protective effects. Studies employing conditions in which such tolerance is not observed, for example, by spacing out intoxication days, would help to elucidate the problem.

\section{Long-Term Effects of EtOH and/or MDMA on Behavior}

Acutely, ethanol alters memory (eg Givens, 1995), motor coordination (eg Gallate et al, 2003; but see Metz et al, 2003), and anxiety-related behaviors (eg Gallate et al, 2003; Langen et al, 2002; Ryabinin, 1998). Beside hyperlocomotion and hyperthermia, MDMA alters motor coordination (Marston et al, 1999), anxiety (Bhattacharya et al, 1998; Morley and McGregor, 2000; Sumnall et al, 2004), and cognitive functions (Braida et al, 2002; Ho et al, 2004; Marston et al, 1999; but see Ricaurte et al, 1993). With exception of the effects described by Cassel et al (2004; see also Rezvani et al, 1992), the acute behavioral effects of both drugs in combination were not studied yet in animals. In the long-term, chronic ethanol treatment may alter cognitive functions (Beracochea and Jaffard, 1991), even after withdrawal (eg Arendt, 1994), and withdrawal from ethanol is anxiogenic (File et al, 1993). MDMA intoxication may produce changes in anxiety-related (McGregor et al, 2003; Morley et al, 2001) and, to some extent, cognitive (eg Marston et al, 1999) behaviors; however, there are no data on long-term effects of both drugs in combination.

Obernier et al (2002) demonstrated that a 4-day binge ethanol exposure induced limbic damage and long-term impairment in cognitive function: intoxicated rats showed normal reference- and working-memory performance in a water-maze task, but were impaired in reversal learning. In the present study, we found a deficit only in the beamwalking test. This task is extremely sensitive to alterations in balance or sensory-motor coordination. For instance, rats with partial lesions of Purkinje cells (eg Thach et al, 1992) show impaired beam walking (eg Lehmann et al, 2000 and unpublished data). One possible reason for the persistence of effect is neuronal loss. Owing to the dose of ethanol used, we believe this is unlikely. Repeated ethanol treatment also induces lasting dysfunction of cerebellar neurons. This possibility would deserve further investigation, but appears compatible with findings showing ethanol-induced dysfunction of Purkinje cells (eg Gruol et al, 1997; Wang et al, 1999).

Rats given MDMA also showed impaired beam-walking performance. Serotonergic depletion may alter balance or sensory-motor coordination (Lehmann et al, 2000; but see Lehmann et al, 2002). MDMA might also directly affect cerebellar (eg granule or Purkinje) cells or perturb their interactions with serotonergic terminals. Thus, it is possible that beam-walking deficits in MDMA-treated rats reflected a long-term alteration of such interactions. Future studies relying upon morphological approaches should contribute to progress on this issue.

MDMA was found to induce anxiety in the long term (Morley et al, 2001). This anxiety was presumably linked to serotonergic toxicity. In the present study, there was clear evidence for serotonergic depletion, indicating that the lack of MDMA-induced anxiety was not due to lack of serotonergic alterations. It is possible, however, that our serotonergic effects were less pronounced than in the
Morley et al study, who, unfortunately, did not report on their serotonergic effects. Despite different testing conditions (eg red light $v s$ white light), both test situations yielded comparable percent time spent in the open arms in controls (about 33\%). A last difference was on the postinjection delay, which was of 19 days herein against 3 months in the study by Morley et al (2001). Thus, it could be that some of the alterations induced by MDMA require some delay before anxiety-related behaviors appear. This speculation seems in line with observations from the literature: long-term anxiogenic effects of MDMA (but see Mechan et al, 2002) were found at postintoxication delays above 4 weeks (Bull et al, 2004; Gurtman et al, 2002; Morley et al, 2001, see also McGregor et al, 2003) against no or small effects at shorter delays (eg Ho et al, 2004; Sumnall et al, 2004).

\section{Long-Term Effects of EtOH and/or MDMA on Evoked 5-HT Release and Its Modulation by Autoreceptors}

Acute alcohol intoxication may influence 5-HT release (eg Bare et al, 1998; Thielen et al, 2002), and so does MDMA (Green et al, 2003 for a review). To our knowledge, the longterm serotonergic effects of a short period of repeated ethanol intoxication are mostly unknown. As to MDMA, several findings pointing towards a reduction of the release of 5-HT after MDMA treatment contrast with our present results (Gartside et al, 1996; Matuszewich et al, 2002; Series et al, 1994; Shankaran and Gudelsky, 1999). Indeed, in rats given MDMA alone, the 5-HT and 5-HIAA concentrations were reduced in various brain regions, but accumulation of $\left[{ }^{3} \mathrm{H}\right] 5-\mathrm{HT}$ in cortical and hippocampal slices, baseline outflow, and electrically evoked overflow of $\left[{ }^{3} \mathrm{H}\right] 5$-HT were close to normal.

This is a first important result of our release experiments. If one omits their findings in the frontal cortex, our data agree with those of Gartside et al (1996). These authors showed that, 2 weeks after intensive treatment with MDMA, (i) the firing activity of dorsal raphé neurons was normal, (ii) the basal release of 5-HT assessed by means of in vivo microdialysis was normal in the frontal cortex and the hippocampus, and (iii) the stimulation of the dorsal or the medial raphe induced an increased 5-HT release in the hippocampus. Interestingly, this stimulated increase was not different between MDMA and saline-treated rats. Thus, despite a marked 5-HT depletion in various brain regions, and particularly in the regions in which evoked 5-HT release has been studied, it appears that normal serotonergic functions can be detected. Gartside et al (1996) attributed this to a capability of unaltered serotonergic terminals to increase their releasable 5-HT pool. This interpretation is compatible with enhanced neurotransmitter release properties described in other lesion models (eg Suhr et al, 1999). Also the modulation of the 5-HT release via autoreceptors, which are of the $5-\mathrm{HT}_{1 \mathrm{~B}}$ subtype, was found to be normal in MDMA-treated rats. Although $5-\mathrm{HT}_{1 \mathrm{~B}}$ receptors may take part in the acute locomotor effects of MDMA (eg Bankson and Cunningham, 2002; Callaway and Geyer, 1992; McCreary et al, 1999), these effects most probably involve $5-\mathrm{HT}_{1 \mathrm{~B}}$ receptors on other neurons, that is, $5-\mathrm{HT}_{1 \mathrm{~B}}$ heteroreceptors. Concerning autoreceptors, we show that their functional characteristics 
are normal despite long-term alterations of tissue-5-HT and 5 -HIAA concentrations.

The second important finding from the release experiments is the apparent change in the modulation of 5-HT release in the hippocampus of rats given ethanol and MDMA in combination. Our data clearly show that the evoked overflow of 5-HT (in percent of tissue- ${ }^{3} \mathrm{H}$ ) in the hippocampus was slightly but significantly increased in the EtOH + MDMA group as compared to the rats treated with saline or EtOH alone (Table 2). This increase in the relative amount of the evoked 5-HT release was observed despite a decrease in hippocampal tissue concentrations of both 5-HT and 5-HIAA (Figure 3). Taken together, these two observations suggest changes in the modulation of 5HT release at the serotonergic axon terminals, changes that appear to lead to a greater amount of transmitter release per individual axon terminal.

Such alterations might either reflect a reduction of inhibitory control mechanisms or an enhancement of facilitatory influences due to the combined treatment with MDMA and EtOH. Interestingly, however, in the hippocampus of these rats, the main presynaptic inhibitory receptor, the $5-\mathrm{HT}_{1 \mathrm{~B}}$ autoreceptor, appeared to be not less, but even significantly more sensitive (Figure 4). Also, in previous studies using rats with fimbria-fornix lesions of hippocampal afferent fibers, an increase in the sensitivity of the 5- $\mathrm{HT}_{1 \mathrm{~B}}$ autoreceptor was observed (Jackisch et al, 1999). Similar lesions cause, however, a significant serotonergic denervation and lead to a decrease of hippocampal 5-HT content and 5-HT release during ongoing stimulation. Therefore, it was possible to show (Jackisch et al, 1999) that the higher potency of the $5-\mathrm{HT}_{1 \mathrm{~B}}$ autoreceptor agonist was only apparent and caused by the diminished competition with the endogenous agonist 5-HT in the vicinity of the autoreceptor ('biophase concentration of 5-HT'). Although a similar interpretation for the present data is further supported by the decrease of the facilitatory effect of the nonselective 5-HT receptor antagonist methiotepin (Figure 4, see also a similar picture in Jackisch et al, 1999), it contrasts with the relative increase of 5-HT release at $S_{1}$ (Table 2), an observation that was, however, also made in rats with fimbria-fornix lesions (Jackisch et al, 1999). In addition, if true, this hypothesis would suppose that changes found in EtOH + MDMA rats should also be present in MDMA rats: this was not the case.

One possibility to account for the apparently paradoxical findings with CP 93,129 and methiotepin would be that methiotepin may alter the release of another transmitter that (i) is not influenced by a drug acting on $5-\mathrm{HT}_{1 \mathrm{~B}}$ receptors, (ii) might interfere with the serotonergic terminal in a way that would oppose to the facilitatory effects of methiotepin on evoked 5-HT release, and (iii) would activate an inhibitory heteroreceptor present on the serotonergic terminal, and which is upregulated after combined ethanol and MDMA treatment. Based on our current state of knowledge, it is not possible to propose a particular receptor. Possible candidates include $\mathrm{GABA}_{\mathrm{A}}$, $\mathrm{GABA}_{B}$, and NMDA receptors (eg Vizi and Kiss, 1998). It could also be that EtOH + MDMA treatment has resulted in an increase of presynaptic facilitatory influences on 5-HT release, which might involve AMPA or $5-\mathrm{HT}_{3}$ receptors (eg Vizi and Kiss, 1998).

\section{Conclusion}

The present results show that repeated treatment with ethanol or/and MDMA produces lasting effects that are manifest in behavior and neurochemistry. Some of these effects may be attributed (i) to MDMA alone, that is, reduced concentrations of 5-HT and 5-HIAA in various brain regions, although 5-HT release capabilities appear normal, (ii) to MDMA alone or to ethanol alone, perhaps by the way of different mechanisms leading to comparable consequences, that is, reduced sensory-motor coordination capabilities, or (iii) specifically to the combination of both drugs, that is, alteration of mechanisms involved in the modulation of 5-HT release in the hippocampus. They also demonstrate that ethanol neither attenuates nor exacerbates effects of MDMA on (i) behavior, or, (ii) levels of 5-HT and 5-HIAA in the cortex and the hippocampus. This is the first study to address delayed effects of MDMA and EtOH, singly and in combination. We conclude that the mechanisms involved in presynaptic modulation of 5-HT release in the hippocampus may be particularly sensitive to this combination. Our findings also suggest that when the recreational use of ecstasy is combined with ethanol, it is possible that the long-term psychopathological problems reported by ecstasy users - which are usually attributed to the 5-HT depleting effect of MDMA - may not be caused solely by the consumption of MDMA. Indeed, we have shown that the combination of MDMA with ethanol may have some longterm consequences on serotonergic functions that MDMA alone does not account for.

\section{ACKNOWLEDGEMENTS}

We thank Ophélie Engasser, Jennifer Kaufling, Claire Lafitte, and Michael Henrique for technical assistance, Olivier Bildstein, Okwandjo Egesi, and George Edomwonyi for animal care. We also thank Kevin Gormley at the National Institute for Drug Abuse for acquisition of the MDMA. This research was supported in part by USPHS Grants NS 35088 and AG 21190, by the Deutsche Forschungsgemeinschaft (Ja 244/51) and the CNRS. BCJ was supported as Professeur Invité at the University Louis Pasteur (Strasbourg, France). We also declare that authors have no involvement that might potentially bias their work. Thank you to Dr Anne Pereira for critical reading of the first and the revised versions of this paper.

\section{REFERENCES}

Arendt T (1994). Impairment in memory function and neurodegenerative changes in the cholinergic basal forebrain system induced by chronic intake of ethanol. J Neural Transm Suppl 44: 173-187.

Badawy AA (1999). Tryptophan metabolism in alcoholism. $A d v$ Exp Med Biol 67: 265-274.

Bankson MG, Cunningham KA (2002). Pharmacological studies of the acute effects of (+)-3,4-methylenedioxymethamphetamine on locomotor activity: role of $5-\mathrm{HT}(1 \mathrm{~B} / 1 \mathrm{D})$ and $5-\mathrm{HT}(2)$ receptors. Neuropsychopharmacology 26: 40-52.

Bare DJ, McKinzie JH, McBride WJ (1998). Development of rapid tolerance to ethanol-stimulated serotonin release in the ventral hippocampus. Alcohol Clin Exp Res 22: 1272-1276. 
Beracochea D, Jaffard R (1991). Effects of chronic ethanol consumption associated or not with experimental anterior thalamic lesions on spontaneous sequential alternation in mice. Neurosci Lett 134: 45-48.

Bhattacharya SK, Bhattacharya A, Ghosal S (1998). Anxiogenic activity of methylenedioxymethamphetamine (ecstasy): an experimental study. Biogenic Amines 14: 217-237.

Braida D, Pozzi M, Cavallini R, Sala M (2002). 3,4-Methylenedioxymethamphetamine (ecstasy) impairs eight-arm radial maze performance and arm entry pattern in rats. Behav Neurosci 116: 298-304.

Bull EJ, Hutson PH, Fone KC (2004). Decreased social behaviour following 3,4-methylenedioxymethamphetamine (MDMA) is accompanied by changes in 5-HT2A receptor responsivity. Neuropharmacology 46: 202-210.

Callaway CW, Geyer MA (1992). Tolerance and cross-tolerance to the activating effects of 3,4-methylenedioxymethamphetamine and a 5-hydroxytryptamine1B agonist. J Pharmacol Exp Ther 263: 318-326.

Cassel JC, Jeltsch H, Koenig J, Jones BC (2004). Locomotor and pyretic effects of MDMA-ethanol associations in rats. Alcohol 34: 285-289.

Clemens KJ, Van Nieuwenhuyzen PS, Li KM, Cornish JL, Hunt GE, McGregor IS (2004). MDMA ('ecstasy'), methamphetamine and their combination: long-term changes in social interaction and neurochemistry in the rat. Psychopharmacology 173: 318-325.

Crews FT, Braun CJ, Hoplight B, Switzer III RC, Knapp DJ (2000). Binge ethanol consumption causes differential brain damage in young adolescent rats compared with adult rats. Alcohol Clin Exp Res 24: 1712-1723.

Darstein MB, Landwehrmeyer GB, Feuerstein TJ (2000). Changes in NMDA receptor subunit gene expression in the rat brain following withdrawal from forced long-term ethanol intake. Naunyn Schmiedebergs Arch Pharmacol 361: 206-213.

Dinopoulos A, Dori I, Parnavelas JG (1993). Serotonergic innervation of the mature and developing lateral septum of the rat: a light and electron microscopic immunocytochemical analysis. Neuroscience 55: 209-222.

Esteban B, O'Shea E, Camarero J, Sanchez V, Green AR, Colado MI (2001). 3,4-Methylenedioxymethamphetamine induces monoamine release, but not toxicity, when administered centrally at a concentration occurring following a peripherally injected neurotoxic dose. Psychopharmacology 154: 251-260.

Esteban S, Moranta D, Sastre-Coll A, Miralles A, Garcia-Sevilla JA (2002). Withdrawal from chronic ethanol increases the sensitivity of presynaptic 5-HT(1A) receptors modulating serotonin and dopamine synthesis in rat brain in vivo. Neurosci Lett 326: 121-124.

File SE, Andrews N, al-Farhan M (1993). Anxiogenic responses of rats on withdrawal from chronic ethanol treatment: effects of tianeptine. Alcohol Alcohol 28: 281-286.

Gallate JE, Morley KC, Ambermoon P, McGregor IS (2003). The consequences of beer consumption in rats: acute anxiolytic and ataxic effects and withdrawal-induced anxiety. Psychopharmacology 166: 51-60.

Gartside SE, McQuade R, Sharp T (1996). Effects of repeated administration of 3,4-methylenedioxymethamphetamine on 5hydroxytryptamine neuronal activity and release in the rat brain in vivo. J Pharmacol Exp Ther 279: 277-283.

Givens B (1995). Low doses of ethanol impair spatial working memory and reduce hippocampal theta activity. Alcohol Clin Exp Res 19: 763-767.

Green AR, Cross AJ, Goodwin GM (1995). Review of the pharmacology and clinical pharmacology of 3,4-methylenedioxymethamphetamine (MDMA or 'Ecstasy'). Psychopharmacology 119: $247-260$.

Green AR, Mechan AO, Elliott JM, O'Shea E, Colado MI (2003). The pharmacology and clinical pharmacology of 3,4-methylene- dioxymethamphetamine (MDMA, 'ecstasy'). Pharmacol Rev 55: 463-508.

Gruol DL, Parsons KL, DiJulio N (1997). Acute ethanol alters calcium signals elicited by glutamate receptor agonists and $\mathrm{K}^{+}$ depolarization in cultured cerebellar Purkinje neurons. Brain Res 773: 82-89.

Gurtman CG, Morley KC, Li KM, Hunt GE, McGregor IS (2002). Increased anxiety in rats after 3,4-methylenedioxymethamphetamine: association with serotonin depletion. Eur J Pharmacol 446: 89-96.

Hernandez-Lopez C, Farre M, Roset PN, Menoyo E, Pizarro N, Ortuno J et al (2002). 3,4-Methylenedioxymethamphetamine (ecstasy) and alcohol interactions in humans: psychomotor performance, subjective effects, and pharmacokinetics. J Pharmacol Exp Ther 300: 236-244.

Ho YJ, Pawlak CR, Guo L, Schwarting RK (2004). Acute and long-term consequences of single MDMA administration in relation to individual anxiety levels in the rat. Behav Brain Res 149: 135-144.

Jackisch R, Haaf A, Jeltsch H, Lazarus C, Kelche C, Cassel JC (1999). Modulation of 5-hydroxytryptamine release in hippocampal slices of rats: effects of fimbria-fornix lesions on 5HT1B-autoreceptor and alpha2-heteroreceptor function. Brain Res Bull 48: 49-59.

Johnson EA, O'Callaghan JP, Miller DB (2004). Brain concentrations of $d$-MDMA are increased after stress. Psychopharmacology 173: $278-286$.

Langen B, Dietze S, Fink H (2002). Acute effect of ethanol on anxiety and 5-HT in the prefrontal cortex of rats. Alcohol 27: 135-141.

Lehmann O, Jeltsch H, Lazarus C, Tritschler L, Bertrand F, Cassel JC (2002). Combined 192 IgG-saporin and 5,7-dihydroxytryptamine lesions in the male rat brain: a neurochemical and behavioral study. Pharmacol Biochem Behav 72: 899-912.

Lehmann O, Jeltsch H, Lehnardt O, Pain L, Lazarus C, Cassel JC (2000). Combined lesions of cholinergic and serotonergic neurons in the rat brain using 192 IgG-saporin and 5,7dihydroxytryptamine: neurochemical and behavioural characterization. Eur J Neurosci 12: 67-79.

LeMarquand D, Pihl RO, Benkelfat C (1994). Serotonin and alcohol intake, abuse, and dependence: findings of animal studies. Biol Psychiatry 36: 395-421.

Lora-Tamayo C, Tena T, Rodriguez A, Moreno D, Sancho JR, Ensenat $\mathrm{P}$ et al (2004). The designer drug situation in Ibiza. Forensic Sci Int 140: 195-206.

Marston HM, Reid ME, Lawrence JA, Olverman HJ, Butcher SP (1999). Behavioural analysis of the acute and chronic effects of MDMA treatment in the rat. Psychopharmacology 144: 67-76.

Matuszewich L, Filon ME, Finn DA, Yamamoto BK (2002). Altered forebrain neurotransmitter responses to immobilization stress following 3,4-methylenedioxymethamphetamine. Neuroscience 110: $41-48$.

McCreary AC, Bankson MG, Cunningham KA (1999). Pharmacological studies of the acute and chronic effects of (+)-3,4methylenedioxymethamphetamine on locomotor activity: role of 5-hydroxytryptamine(1A) and 5-hydroxytryptamine(1B/1D) receptors. J Pharmacol Exp Ther 290: 965-973.

McGregor IS, Clemens KJ, Van der Plasse G, Li KM, Hunt GE, Chen F et al (2003). Increased anxiety 3 months after brief exposure to MDMA ('Ecstasy') in rats: association with altered 5-HT transporter and receptor density. Neuropsychopharmacology 28: $1472-1484$.

Mechan AO, Esteban B, O'Shea E, Elliott JM, Colado MI, Green AR (2002). The pharmacology of the acute hyperthermic response that follows administration of 3,4-methylenedioxymethamphetamine (MDMA, 'ecstasy') to rats. Br J Pharmacol 135: 170-180.

Metz GA, Gonzalez CL, Piecharka DM, Whishaw IQ (2003). Acute alcohol administration improves skilled reaching success in 
intact but not 6-OHDA dopamine depleted rats: a subsystems analysis of the motoric and anxiolytic effects of alcohol. Behav Brain Res 142: 167-174.

Molliver ME, Berger UV, Mamounas LA, Molliver DC, O'Hearn E, Wilson MA (1990). Neurotoxicity of MDMA and related compounds: anatomic studies. Ann NY Acad Sci 600: 649-661.

Morley KC, Gallate JE, Hunt GE, Mallet PE, McGregor IS (2001). Increased anxiety and impaired memory in rats 3 months after administration of 3,4-methylenedioxymethamphetamine ('ecstasy'). Eur J Pharmacol 433: 91-99.

Morley KC, Li KM, Hunt GE, Mallet PE, McGregor IS (2004). Cannabinoids prevent the acute hyperthermia and partially protect against the 5-HT depleting effects of MDMA ('Ecstasy') in rats. Neuropharmacology 46: 954-965.

Morley KC, McGregor IS (2000). (+/-)-3,4-Methylenedioxymethamphetamine (MDMA, 'Ecstasy') increases social interaction in rats. Eur J Pharmacol 408: 41-49.

Obernier JA, White AM, Swartzwelder HS, Crews FT (2002). Cognitive deficits and CNS damage after a 4-day binge ethanol exposure in rats. Pharmacol Biochem Behav 72: 521-532.

Oesterheld JR, Armstrong SC, Cozza KL (2004). Ecstasy: pharmacodynamic and pharmacokinetic interactions. Psychosomatics 45: 84-87.

Pacifici R, Zuccaro P, Hernandez Lopez C, Pichini S, Di Carlo S, Farre $M$ et al (2001). Acute effects of 3,4-methylenedioxymethamphetamine alone and in combination with ethanol on the immune system in humans. J Pharmacol Exp Ther 296: 207-215.

Parrott AC, Milani RM, Parmar R, Turner JD (2001). Recreational ecstasy/MDMA and other drug users from the UK and Italy: psychiatric symptoms and psychobiological problems. Psychopharmacology 159: 77-82.

Pedersen W, Skrondal A (1999). Ecstasy and new patterns of drug use: a normal population study. Addiction 94: 1695-1706.

Rezvani AH, Garges PL, Miller DB, Gordon CJ (1992). Attenuation of alcohol consumption by MDMA (ecstasy) in two strains of alcohol-preferring rats. Pharmacol Biochem Behav 43: 103-110.

Ricaurte GA, Markowska AL, Wenk GL, Hatzidimitriou G, Wlos J, Olton DS (1993). 3,4-Methylenedioxymethamphetamine, serotonin and memory. J Pharmacol Exp Ther 266: 1097-1105.

Ryabinin AE (1998). Role of hippocampus in alcohol-induced memory impairment: implications from behavioral and immediate early gene studies. Psychopharmacology 139: 34-43.

Sabol KE, Lew R, Richards JB, Vosmer GL, Seiden LS (1996). Methylenedioxymethamphetamine-induced serotonin deficits are followed by partial recovery over a 52-week period. Part I: Synaptosomal uptake and tissue concentrations. J Pharmacol Exp Ther 276: 846-854.

Scanzello CR, Hatzidimitriou G, Martello AL, Katz JL, Ricaurte GA (1993). Serotonergic recovery after (+/-)3,4-(methylenedioxy) methamphetamine injury: observations in rats. J Pharmacol Exp Ther 64: 1484-1491.

Schifano F (2004). A bitter pill. Overview of ecstasy (MDMA, MDA) related fatalities. Psychopharmacology 173: 242-248.

Schmidt CJ, Levin JA, Lovenberg W (1987). In vitro and in vivo neurochemical effects of methylenedioxymethamphetamine on striatal monoaminergic systems in the rat brain. Biochem Pharmacol 36: 747-755.

Schmued LC (2003). Demonstration and localization of neuronal degeneration in the rat forebrain following a single exposure to MDMA. Brain Res 974: 127-133.

Series HG, Cowen PJ, Sharp T (1994). p-Chloroamphetamine (PCA), 3,4-methylenedioxy-methamphetamine (MDMA) and $d$ fenfluramine pretreatment attenuates $d$-fenfluramine-evoked release of 5-HT in vivo. Psychopharmacology 116: 508-514.

Shankaran M, Gudelsky GA (1999). A neurotoxic regimen of MDMA suppresses behavioral, thermal and neurochemical responses to subsequent MDMA administration. Psychopharmacology 147: 66-72.

Steinbusch HW (1981). Distribution of serotonin-immunoreactivity in the central nervous system of the rat-cell bodies and terminals. Neuroscience 6: 557-618.

Suhr R, Balse E, Haaf A, Kelche C, Cassel JC, Jackisch R (1999). Modulation of acetylcholine and 5-hydroxytryptamine release in hippocampal slices of rats with fimbria-fornix lesions and intrahippocampal grafts containing cholinergic and/or serotonergic neurons. Brain Res Bull 50: 15-25.

Sumnall HR, O'Shea E, Marsden CA, Cole JC (2004). The effects of MDMA pretreatment on the behavioural effects of other drugs of abuse in the rat elevated plus-maze test. Pharmacol Biochem Behav 77: 805-814.

Thach WT, Goodkin HP, Keating JG (1992). The cerebellum and the adaptive coordination of movement. Annu Rev Neurosci 15: 403-442.

Thielen RJ, Bare DJ, McBride WJ, Lumeng L, Li TK (2002). Ethanol-stimulated serotonin release in the ventral hippocampus: an absence of rapid tolerance for the alcohol-preferring $\mathrm{P}$ rat and insensitivity in the alcohol-nonpreferring NP rat. Pharmacol Biochem Behav 71: 111-117.

Thielen RJ, Engleman EA, Rodd ZA, Murphy JM, Lumeng L, Li TK et al (2004). Ethanol drinking and deprivation alter dopaminergic and serotonergic function in the nucleus accumbens of alcohol-preferring rats. J Pharmacol Exp Ther 309: 216-225.

Vasconcelos SM, Macedo DS, Lima LO, Sousa FC, Fonteles MM, Viana GS (2003). Effect of one-week ethanol treatment on monoamine levels and dopaminergic receptors in rat striatum. Braz J Med Biol Res 36: 503-509.

Vizi ES, Kiss JP (1998). Neurochemistry and pharmacology of the major hippocampal transmitter systems: synaptic and nonsynaptic interactions. Hippocampus 8: 566-607.

Wang X, Baumann MH, Xu H, Rothman RB (2004). 3,4methylenedioxymethamphetamine (MDMA) administration to rats decreases brain tissue serotonin but not serotonin transporter protein and glial fibrillary acidic protein. Synapse 53: 240-248.

Wang Y, Freund RK, Palmer MR (1999). Potentiation of ethanol effects in cerebellum by activation of endogenous noradrenergic inputs. J Pharmacol Exp Ther 288: 211-220.

Winer BJ (1971). Statistical Principles in Experimental Design. McGraw-Hill: New York.

Zou JY, Martinez DB, Neafsey EJ, Collins MA (1996). Binge ethanol-induced brain damage in rats: effect of inhibitors of nitric oxide synthase. Alcohol Clin Exp Res 20: 1406-1411. 